\title{
Clontarf to Curtin: Row AHEAD and Tertiary Affinity
}

\author{
Cameron Thorn \\ Curtin AHEAD, Curtin University \\ cameron.thorn@curtin.edu.au
}

Charles Flodin

Curtin AHEAD, Curtin University

charles.flodin@curtin.edu.au

Keywords: school, outreach, Indigenous, engagement, rowing.

\section{Introduction}

In Western Australia, and around the world, rowing is a sport that is often associated with elite private schools and tertiary institutions (Cambridge University Boat Club, 2013; Yale Athletics, 2010; Oxford University Boat Club, 2015; Melbourne University Boat Club, 2015). Events like the Boat Race, an annual rowing event for the top Oxford and Cambridge University crews, and the Henley Royal Regatta, held on the Thames River since 1839, serve to reinforce the elitist history of the sport. In a more local context, rowing in Western Australia is predominantly facilitated by a number of high-fee-paying secondary schools running their own competitions for male and female students throughout the year.

Despite the majority of these schools supporting Indigenous students via full academic and boarding scholarships, it is estimated that a maximum of 20 Indigenous students have participated in rowing in some way over the past 10 years. On a national level, Indigenous participation is estimated to be about $0.01 \%$ (L. Callier, pers. comm. May 8, 2014). The program designers believed it was worth noting that Indigenous higher education students make up around $2 \%$ of the national higher education student body (Australian Bureau of Statistics, 2011). The designers believed that these participation rates were worth highlighting, given the historical development of the sport of rowing, and could add value to the delivery of the program and narrative of the participant journey, resulting from an increase in engagement. $A$ program was designed to engage Indigenous students in the sport of rowing, and support them through an aspiration and awareness-raising curriculum.

Row AHEAD, as a pilot developed by Curtin AHEAD (Addressing Higher Educational Access Disadvantage), engages Indigenous students from Clontarf Aboriginal College in a 12 week program of self-development. Clontarf Aboriginal College, located in Manning, Western Australia, was opened as an Indigenous boys school in 1986, with 50 students enrolling from regional and remote Western Australian communities (Clontarf Aboriginal College, 2015). Since then, the College has developed to cater for over 150 Indigenous male and female student placements annually, from across Western Australia and the Northern Territory.

For the Row AHEAD program, students take part in weekly training sessions: water sessions, held at Curtin University Boat Club, to improve their rowing specific skills; and, land sessions, held at Curtin Stadium, to improve overall fitness. Activities are also designed so that students build their confidence, resilience and team skills. Students train toward competing in the Rowing WA All Schools Championships, representing their school and community. As a part of the initiative, students are required to attend weekly development sessions. The curriculum developed for students to complete has been approved by SCASA (School Curriculum and Standards Authority) as a WACE (Western Australian Certificate of Education) unit. 


\section{Motivation for program design}

A significant driver of the program is that, to date, Row AHEAD has been funded through HEPP and as such is also focused on the overarching objectives that align with this source of federal funding; to improve the understanding and awareness of higher education (Higher Education Support Act 2003). Through the program we sought to devise a pragmatic approach to raising the aspirations and awareness of the participant student group to higher education. Our core cohort of students were not on a direct study path to university, with participants demonstrating various levels of engagement with education. We recognised the rational concerning aspiration and awareness needed to be built on the foundation of creating a knowledge base, from previous outreach experience, to enable students to make informed decisions in a post-school non-tertiary focused environment and potentially outside of the support network of the program itself. The pilot program focused on a mixed age cohort of Indigenous students, due to student access and time challenges. It was decided in collaboration with Clontarf Aboriginal College that the pursuit of outcomes, relating to the forming of aspirations and effective awareness of higher education, was best trialled with those students whom self-selected into the program. Taken into consideration also, during program planning, was the fact that students may not only feel unprepared for university in terms of academic ability or social relevance, they may also have concerns or be influenced by the fear of transitioning into a new perceived social strata. This concern could manifest as anxiety around leaving their social norms and entering a knowledge society, which sets ideals and expectations at a distance from their friends and family. Research shows that some students reference transition as "a risk of 'changing' class identity as a result of participation in higher education" (Archer, Leathwood \& Hutchings 2002, p.112)

The Victorian Department of Education and Early Childhood Development found that "disengaged learners develop social distance from education and training, which any subsequent outreach needs to break through" (2011). The Row AHEAD program needed to be designed and implemented in a way that fostered social engagement between participants, and also between internal and external stakeholders. In a recent study of sports programs around Australia it was found that "sports programs appear to have distinct capacities to contribute to broad based community development and in the case of Australia contribute to the Closing The Gap blueprint" (Rossi 2015, p 192). Having considered various elements needed to generate the best outcomes for participants, the program proactively sought to deliver a shared platform through which to explore context driven conversation that could deliver awareness and aspiration raising strategy through the activity of rowing and the supportive framework of the rowing club.

\section{Tertiary affinity}

It was the contention of the program, that any traditional university outreach activities (University experience days, awareness workshops, university course selection and so on) would be too disconnected as an experience and too abstract as a concept, to gain immediate traction with the lived realities of our participant cohort. The rowing club offered a unique opportunity to engage our participants directly in the formal social framework of the university campus. It was noted throughout the evaluation of the program that participants were able to feel a sense of belonging in an environment to which they contributed, alongside graduates and university students. This strategy formed what was to become the foundation of our outreach methodology. It created a vehicle through which to informally raise aspirations, awareness and capability of higher education. We termed the strategy 'tertiary-affinity'. 
University offers an opportunity to focus on a more personalised learning journey, connected to a progression into the world of higher education. The successful transition into this environment, involves planting the seed of both academic and social belonging:

"Feedback suggests that universities generally display a low level of awareness of Australian Indigenous culture and peoples, and this often results in poor communication, little understanding of Indigenous communities, and the diverse needs of its current or future Indigenous students" (Ridgeway, 2012).

The program to this extent, seeks to introduce an element of humanising pedagogy. Taking inspiration from Freire, the programs "pedagogy had to be meaningful in order to be critical and transformative" (Giroux, 2010). The student's personal experiences, both past and those being created through the program activities and location, became key resources in the relationship of the students to the learning outcomes of the program. Tertiary-affinity as an outcome, seeks to create an environment or vehicle through which those students, traditionally not represented at university, can begin finding an internal locus of meaningful belonging within a tertiary institution. As an outcome, tertiary affinity does not assume that the student should, will or can transition into university at the commencement of the program but recognises that for a person to choose to pursue a higher education pathway, they must believe that they can achieve that goal as well as feel like they will be able to connect to the tertiary environment on a social level.

Universities are multicultural and diverse institutions, however this does not directly equate to being a place that everyone feels able to be part of. Inclusion does not just manifest in academic ability, recognition of academic or sporting potential or the creation of alternative pathways. Inclusion incorporates both external and internal emotional mechanisms that require development. Tertiary-affinity moves beyond making someone feel like they are capable of being accepted into a closed environment and moves to foster a growth in the social capital that offers students the opportunity to form a conceptual relationship through which they can connect to the tertiary landscape and engage in meaningful dialog. It establishes a lens through which to visualize oneself in a new environment within a safe and empowered context.

Tertiary-affinity programs, such as Row AHEAD, establish social dynamics that have the capacity to let students feel like they have chosen to be part of a tertiary ecosystem, through which they associate with having an inherent connection and attraction. Tertiary-affinity seeks to normalise discourse surrounding higher education and university environments, by developing deeper parity between the local community and University, where it is natural and appropriate to do so.

\section{Partnership building}

A key element in the partnership design is the emphasis on a balanced relationship, which informs the social contract between key stakeholders, built around shared and explicit outcomes. Key partners of the 2014 program include Clontarf Aboriginal College, Curtin AHEAD, Curtin University Boat Club, Rowing WA and Curtin Stadium. Program activities were defined within a service agreement detailing terms of engagement and responsibilities. The agreement is driven by a program proposal which outlines the core philosophy, aims and objectives.

The key relationships contribute to the development of the social framework, recognising the influence and significance of the multiple perspectives, held within the program community. Thus the partnerships were built around an acknowledgment and celebration of the unique nature of partner objectives and ownership of distinct service elements of the program. This allowed for an efficient and practical division of labour, with partners focusing on their areas 
of expertise to the benefit of the participants. By bringing all partners along on the journey, from conception to completion, it was found that all expectations regarding partnership were exceeded.

The program outcomes, targeting the raising of aspirations awareness and capabilities for higher education, are inherently linked to the additional mutual outcomes, established within the partnerships, which enhance partner social frameworks as well as seeing the emergence of a new-shared social paradigm. Armstrong \& Cairnduff (2012) emphasise that "Universities have a major contribution to make in forming communities and not just responding to the needs of different communities." The Row AHEAD program operated within an element of the University social structure i.e. university social sports, which represented an ideal opportunity to further develop community relationships. This approach to program design and the established positive outcomes emphasise that "Utilising existing relevant community structures and disseminating relevant information in appropriate ways, there is potential to bring about real change relating to higher education access" (Scull \& Cuthill, 2010).

One key advantage of this type of initiative is that "university" is not the focal point of the partnership. The activity and the society that participants are encouraged to become a part of, only forms an aspect of the university environment and is in very real terms more accessible and less daunting. It is also an environment that represents a support network and dynamic that students can have a realistic and immediate impact on, in terms of bringing and sharing their own culture and identity.

It is important to highlight the significance and impact of the partnership between the Clontarf Aboriginal College participants and their rowing coaches, who were undergraduates studying at Curtin University. During the establishment phase and first few weeks of the program, it wasn't very clear what other outcomes would be measureable. However for the majority of the coaches, this was the first time they had engaged with and supported Indigenous participants. Solidarity and collegiality formed key tenets of the approach to partner engagement. The Clontarf students were recognised as partners of the program as much as participants. Many of the coaches, and also the student participants, had to overcome their own cultural barriers to engage with others in a meaningful way and contribute to the overall success of the program.

\section{Program outline}

Row AHEAD is set up as a twelve-week program, with outcomes linked to HEPP funding objectives of raising aspiration and awareness of higher education. The initiative is broken down into two phases: learning to row and competition. These phases dictate the focus for each session and establish the progression of the program. There are a number of components that make up the program, that participants are expected to take part in, including: two water training sessions per week, rowing specific, held at Curtin University Boat Club; one land training session per week, general fitness, held at Curtin Stadium; and one academic session per week, held at the Ngulla Mia Boarding Facility. Through the establishment of rowing as the common thread between all facets of the program, therefore the tool for engagement, the program was designed to follow the notion that student engagement is a fundamental element in retention and promoting achievement (Shin, Daly \& Vera, 2007). Activities are built around an action learning model, to ground learning in an experiential framework that fosters interest, engagement and collaborative learning dynamics.

For the first phase the participants from Clontarf Aboriginal College undergo a condensed Learn to Row program, during which they are taught the correct technique of the sport and become accustomed to the equipment used. This process begins with students being supervised using 
exercise rowing machines at Curtin University Boat Club and Curtin Stadium, and finish with students confidently navigating a Single Scull across a one kilometre stretch of water, on the Canning River between Clontarf Aboriginal College and Curtin University Boat Club. This phase connects students to their coaches and the tertiary environment, and familiarises them with the physical space around the College and parts of the Curtin University campus.

The second phase begins with students training in crew boats - quads and eights. The students learn to race in both Sweep and Scull style boats, ensuring they have a good understanding of all facets of the sport. Once the students have demonstrated competence rowing as a crew over a one kilometre distance, they will begin representing their school and competing in the Rowing WA All Schools Competition. The participants compete in various boat classes over the series of regattas, depending on eligibility for competition. A final community regatta is held at Curtin University Boat Club, supported by Rowing WA, titled Clontarf to Curtin. This is an opportunity for all participants to row in crew boats alongside their coaches and other volunteers from Curtin University Boat Club, physically completing the journey on the water from Clontarf to Curtin, celebrating the completion of the program and success of the rowers.

Each component of the program provides new and unique learning opportunities for participants, all linking back to rowing and supporting on-going communication and relationship building between participants and their coach, tutor or trainer. The water and land training sessions focus on the development of self-efficacy of the participants, as well as specific skill development. The weekly academic development sessions focus on integrating the student's interest of rowing, with the development of their literacy and numeracy skills. Learning activities are also structured, with the support of the Aboriginal and Islander Education Officer (AIEO) from Clontarf Aboriginal College and the Elder in Residence at Curtin University, throughout the program to support the development of Indigenous culture and identity within rowing and the wider community.

The team is made up of teachers, rowing coaches and university ambassador coaches. The organisational structure creates the potential for a positive student-teacher dynamic and enables role model relationships to develop organically. These relationships have great potential to extend beyond the duration of the program, through the planned long-term relationship between the program and Clontarf College, as well as the potential for students to continue their rowing journey through Curtin University Boat Club as on-going members.

\section{Program outcomes}

Row AHEAD was designed to support students from Clontarf Aboriginal College to achieve outcomes that were identifiable as new opportunities and learning experiences. With a focus on social engagement leading to development, participants were able to access and participate in a new sport and learning opportunities while taking part in meaningful engagement with current university students. Through the development and completion of the curriculum component of the program, facilitated by the academic sessions, participants also received academic support across school curriculum as well as support to develop ownership of the sport through pride in Indigenous identity, culture and spirituality. The program also promoted and supported students in the development of their own personal goals, consideration and exploration of vocational opportunities, as well as leading to an increase in student's awareness of how to improve their own personal health and wellbeing.

An evaluation of the pilot was developed as the program progressed, providing on-going feedback to the program designers and facilitators. The evaluation was designed to be appropriate for children through the following mechanisms; a parental consent form was used 
to disseminate information to parents and guardians about the program and provide consent for their student/s to opt in, appropriate language (verbal and written) was used throughout the evaluation process, and all of the staff and coaches have valid working with children checks and undergo cultural awareness training. A formal ethics clearance has been requested for the 2016 program, having been tentatively accepted in late 2015.

Anecdotal feedback from students and staff from Clontarf Aboriginal College, as well as those from Curtin University, has been overwhelmingly positive. The program has exceeded initial expectations from the designers; with in excess of 50 students showing interest in the program, 25 trying out and 19 successfully completing the program. The cohort of students who completed the program are from different year groups, year 8-12, and comprised of a $1: 3$ ratio of male to female students. The initial draft had an aspiration to engage 10 students in the program, with hopes of four students taking part in the Rowing WA All School State Championship.

It has been observed that all participants have learnt how to row and show confidence when rowing in scull and sweep style boats; all participants are able to row effectively and in a technically proficient manner as individuals and in crew boats. This is due to participants completing all elements of the program, meeting expectations set within the group by students and coaches. This has led to improved fitness and willingness to engage in physical exercise, something that a few of the students had previously profusely objected and actively avoided. Additionally many staff around the College have reported that participation in the program has also brought on a positive shift in attitude, shown by the students, toward engaging in school and activities, specifically being active participants in the class, and demonstrating an increased willingness to learn.

The curriculum and workbook, that participants are required to complete, has been approved by the Western Australian Department of Education to be a full unit endorsed program. Participants who complete this program will have less school subject results assessed across year 11 and 12, as part of meeting requirements for high school graduation. As a result some students may immediately be eligible for entry into higher education institutions, or have more options available to them than those who do not complete the program. This recognition by the School Curriculum and Standards Authority highlights the positive impact that the program has on participants, and their commitment and resilience to complete the program. As a result of participating in the pilot, several participants have expressed, anecdotally, their desire to pursue a health science or sports science related university course. These students are receiving additional support and guidance to work toward their new goals.

The development of a uniform to wear when participating in competition was also designed by students, as a learning activity within the curriculum. The students were provided with templates from which to adapt to create their own zoot suit - the competition uniform worn by rowers. As part of this process, participants had to explain and justify their design and explore the link back to the College and their own Indigenous identity. Four designs were picked and elements from each were combined into a final design that was approved by the College and local Elders. It was important to empower the students to create a unique identity, which made rowing their own and to which all partners could be invited, to support and collaborate in. The final zoot suit was produced and given to all participants from the program, as a symbol of ownership of access to the sport and wider opportunities. Clontarf Aboriginal College has adopted the zoot suit, designed by students, as their official rowing uniform. The students wear the zoot suit with pride when representing themselves, the College, and the wider Indigenous community. 
A critical outcome of the program was the engagement in the sport by Indigenous participants. As previously noted, participation in the sport or rowing nationally by Indigenous participants is extremely low (L. Benjamin, personal communication, June 22, 2015). Importantly on the 26th July, 2014, sixteen Clontarf Aboriginal College students fulfilled the significant milestone of forming the first Indigenous rowing squad to take part in a state regatta, representing their school in the Rowing WA All School Championship. With validation from Rowing Australia (D. Tackenberg, personal communication, February 22, 2015), these students made up the first all Indigenous squad to compete nationally in a sanctioned regatta. The program impact has gone beyond student engagement and examples of its influence on the wider national rowing community, as well as Clontarf Aboriginal College physical education curriculum, are beginning to become apparent.

\section{Conclusion: Insights into implications for policy and practice:}

It could be argued that outreach policy in Australia does not adequately articulate or empower programs to work from or analyse the platform of knowledge that establishes the relationship between university and community (those communities traditionally underrepresented within higher education). For example a 2011 Department of Education, Employment and Workplace Relations paper, that conducted a literature review, relating to the current context and discourse of Indigenous Tertiary Education in Australia, found that a dominant theme that had emerged was the "need to value and embed Indigenous knowledge and perspectives throughout all levels of the university".

Policy and funding tends to emphasise those transactional outcomes that may only empower those individual students that directly demonstrate the potential to transition into higher education: "widening participation strategies often fail because they are 'a-theoretical' in their approaches, both failing to specify how they conceptualise social class and failing to theorise the role of higher education within society" (Armstrong \& Cairnduff, 2012, p. 921) Greater emphasis could be placed on looking beyond access and participation as operational targets and working toward community participation as an extension of the university environment - a symbiotic relationship driven by values, underpinned by deeper understanding of the impact and consequences of Higher Education access and participation. As such the Row AHEAD program is as much about the importance of the relationship with the partner institution and their journey to better outcomes for their future students, as with the current program participants.

Armstrong and Cairnduff (2012), utilise an analogy to further illustrate a theoretical division within higher education and the creation of subsequent barriers to entry. The analogy depicts 'two nations' - those who are part of the knowledge economy (via higher education) and those separated by their 'otherness' (educational failure), creating a chasm in which the culture and practices of higher education represent as equal a barrier to access as educational failure. The Row AHEAD program, within this context, has focused on the social and cultural epochs of the university environment as the foundation of the programs outcomes. This in part has been influenced by the demographic of students that form the participants. The students are not on a direct or traditional university pathway and so outreach rooted in standard academic capacity building, for the purposes of aspiration raising, were inappropriate. In point of fact a partner institution had begun disengaging with many of the wider programs activities, as it was felt that, although they were tertiary aspiration programs, they could not resonate with their students and would likely not have the intended impact.

Scull and Cuthill (2010) suggest that, "traditional university outreach programs are too narrowly focused and fail to target the full range of key players who influence an individual's decision to attend university" (p.60). This resonates with the AHEAD programs experience in effective 
communication with partners, which drive the positive outcomes. Our experiences lend weight to the argument for universities to invest in working within their local context, to engage with multiple stakeholders, covering a variety of variables that impact a student forming the decision to pursue a university pathway. For programs to be judged on the very narrow parameters of student applications or transitions into university - is in itself a potential barrier to the formation of effective programs. The Row AHEAD program is establishing positive outcomes that have a focus on character development and aspects of more ingrained challenges that manifest as a lack of self-belief, self-awareness and self-motivation. There is a deeper focus on establishing the development of social capital for participants and this is seen as increasingly important in student decision making and experiences relating to higher education. Ball, Davies, David, \& Reay (2002) explain that in regards to higher education and social diversity a number of important factors impact the available choices regarding access; social capital, material constraints and social perceptions. The policies that may inform the operational and methodological approaches to increasing higher education access and participation, may create an environment that does not enable practitioners the remit or time necessary to focus attention on establishing rich and sustainable relationships within local communities. It is within these communities, that transition issues that go beyond the capability deficit and speak to emotional pressure points, can be nourished and tackled within a community of support.

A reflection on the Row AHEAD program indicates that a greater emphasis on the aspirational activation of the physical environment, as an extension of the university campus, as well as greater reflection on the local and cultural knowledge base of participants is key in establishing the benefits of a mixed methods outreach strategy. "Taken together, phenomenologists, cultural critics, bio-regionalists, eco-feminists, and others show that places teach us who, what, and where we are, as well as how we might live our lives". (Gruenewald, 2003, p 636). Row AHEAD, as an element of Curtin AHEAD, tackles both capacity building and developing communities of support. Many Indigenous students disengage from school, or don't see the value in education, as a result of how their teachers portray their future, they don't see themselves in it (Harrison, 2011). Row AHEAD is a product of intense community involvement, utilising locally controlled resources and places, managed and facilitated in a way that is respectful toward the Indigenous students and the school community. Row AHEAD fosters the development of tertiary affinity in the participants without utilising a deficit model, avoiding implications that existing aspirations are inferior and require intervention.

\section{References:}

Archer, L., C. Leathwood, \& M. Hutchings. (2002). Higher education: A risky business. In A. Hayton and A. Paczuska (Eds.) Participation and higher education: Policy and practice. London: Kogan Page.

Armstrong, D., \& Cairnduff, A. (2012). Inclusion in higher education: issues in university-school partnership. International Journal of Inclusive Education, 16(9), 917-928. DOI: $10.1080 / 13603116.2011 .636235$

Australian Bureau of Statistics. (2011). Hitting the books: Characteristics of higher education students (No. 4102.0). Retrieved from http://www.abs.gov.au

Australian Council for Educational Research. (2011). Literature Review relating to the current context and discourse of Indigenous Tertiary Education in Australia. Retrieved from https://docs.education. gov.au/system/files/doc/other/australian_council_for_educational_research_2011.pdf

Ball, S., Davies, J., David, M., \& Reay, D. (2002). "Classification” and “Judgement”: Social Class and the "Cognitive Structures" of Choice of Higher Education, (July 2015).

DOI: 10.1080/01425690120102854. 
Cambridge University Boat Club. (2013). The History: the club and the race. Retrieved from http://www. cubc.org.uk/history/

Clontarf Aboriginal College. (2015). Parent Handbook. Retrieved from http://web.clontarf.wa.edu.au/wpcontent/uploads/2015/05/Clontarf-Parent-Handbook-2015.pdf.

Giroux, H.A. (2010, November 23) Lessons to be learned from Paulo Freire as education is being taken over by the mega rich.

Retrieved from http://truth-out.org/archive/component/k2/item/93016:lessons-to-be-learned-frompaulo-freire-as-education-is-being-taken-over-by-the-mega-rich.

Gruenewald, D.A. (2003). Foundations of Place: A Multidisciplinary Framework for Place-Conscious Education. American Educational Research Journal, 40(3), 619-654. DOI: 10.3102/00028312040003619.

Harrison, N. (2011). Teaching and Learning in Aboriginal Education. South Melbourne, Australia: Oxford University Press.

Higher Education Support Act 2003 (Cth). Higher Education Participation and Partnerships Program.

Melbourne University Boat Club. (2015). About MUBC. Retrieved from http://www.mubc.asn.au/about. html.

Oxford University Boat Club. (2015). About: the club. Retrieved from http://www.oubc.org.uk/about.

Ridgeway, A. (2012). Indigenous higher education review. Retrieved from https://docs.education.gov.au/ system/files/doc/other/cox_inall_ridgeway_2012.pdf.

Rossi, T. (2015). Expecting too much? Can Indigenous sport programmes in Australia deliver development and social outcomes. International Journal of Sport Policy and Politics, 7(2), 181-195.

Scull, S., \& Cuthill, M. (2010). Engaged outreach: using community engagement to facilitate access to higher education for people from low socio-economic backgrounds. Higher Education Research \& Development, 29(1), 59-74. DOI: 10.1080/07294360903421368.

Shin, R., Daly, B., \& Vera, E. (2007). The relationships of peer norms, ethnic identity, and peer support to school engagement in urban youth. Professional School Counselling, 10(4), 379-388.

Victorian Department of Education and Early Childhood Development. (2011). Strategic Review of Effective Re-Engagement Models for Disengaged Learners (Report).

Yale Athletics. (2010). Yale crew championships and highlights. Retrieved from http://www.yale.edu/ rowing/lt_history.html. 